\title{
Challenges in Predicting Cognitive Decline in Dementia with Lewy Bodies
}

\author{
Konstantinos Tsamakis ${ }^{a, b} \quad$ Christoph Mueller ${ }^{a, c}$ \\ anstitute of Psychiatry, Psychology and Neuroscience, King's College London, London, UK; \\ bSecond Department of Psychiatry, School of Medicine, University General Hospital 'ATTIKON', Athens, Greece; \\ 'South London and Maudsley NHS Foundation Trust, London, UK
}

\section{Keywords}

Dementia with Lewy bodies · Cognition · Fluctuations ·

Delirium · Multiple neuropathologies

\begin{abstract}
Despite being the second most common form of neurodegenerative dementia, dementia with Lewy bodies (DLB) is under-recognized and carries a worse prognosis than other subtypes of the condition. Cognitive impairment is a cardinal feature of all types of dementia and DLB presents with a distinct profile with deficits in attention, executive function, and visuoperceptual abilities. This difference from Alzheimer's disease and the common presence of neuropsychiatric symptoms may lead to challenges in predicting cognitive decline in this patient population. Firstly, the diagnosis of DLB is often delayed in clinical practice leading to variability from which time point in the disease course cognitive decline is measured. Secondly, the most frequently used measurement tools for cognitive difficulties focus on memory and naming rather than the domains affected by DLB. While there is now largely a consensus which tools are useful in diagnosing DLB, their validity in assessing deteriorating cognition is less clear. Thirdly, the presence of fluctuating cognition, the propensity to develop delirium episodes, as well as difficulties in distinguishing the two entities in clinical prac-
\end{abstract}

karger@karger.com www.karger.com/dem

Karger $\stackrel{\text { ' }}{5}$

GOPEN ACCESS
(C) 2021 The Author(s)

Published by S. Karger AG, Basel

This is an Open Access article licensed under the Creative Commons Attribution-NonCommercial-4.0 International License (CC BY-NC) (http://www.karger.com/Services/OpenAccessLicense), applicable to the online version of the article only. Usage and distribution for commercial purposes requires written permission. tice make it difficult to predict the disease course. Sleep disturbances are likely to influence cognitive decline but require further study in patients within established DLB. Fourthly, as in most cases of dementia, neuropathological comorbidities are frequently present in DLB. While the influence of Alzheimer's pathology on cognitive decline in DLB is comparatively well understood, the impact of other pathologies remains unclear. The recent definition of research criteria for mild cognitive impairment in DLB could facilitate earlier diagnosis and more structured follow-up. Assessment tools measuring cognitive domains predominantly affected in DLB need to be more consistently used in longitudinal studies and clinical practice, as well as concurrent measures of fluctuations in cognition. Greater availability of biomarkers and digital healthcare solutions can play an important role in enabling more accurate monitoring and prediction of cognitive decline in DLB.

(c) 2021 The Author(s)

Published by S. Karger AG, Basel

\section{Introduction}

Dementia with Lewy bodies (DLB) is the second most common form of neurodegenerative dementia. While neuropathological case studies report incidences of 15$20 \%$ [1], this is considerably lower in routine clinical ser- 
Table 1. Overview of challenges, clinical considerations, and research directions

\begin{tabular}{|c|c|c|}
\hline Challenge & Clinical considerations & Research directions \\
\hline \multirow[t]{2}{*}{ Delayed diagnosis of DLB } & $\begin{array}{l}\text { Proactively diagnose MCI and consider the possibility of } \\
\text { Lewy body pathology }\end{array}$ & $\begin{array}{l}\text { Prospective studies on how patients with MCI-LB } \\
\text { progress to dementia }\end{array}$ \\
\hline & $\begin{array}{l}\text { Severe presentations of new-onset mental illness in old age } \\
\text { could be in the context of (prodromal) DLB }\end{array}$ & $\begin{array}{l}\text { Monitoring of cognitive decline in those who have been } \\
\text { diagnosed with DLB following a previous MCI or MCI- } \\
\text { LB diagnosis }\end{array}$ \\
\hline & (MoCA) as screening tool and ror rollow-up assessments & $\begin{array}{l}\text { Further studies to assess decline in individual cognitive } \\
\text { domains }\end{array}$ \\
\hline \multirow[t]{2}{*}{$\begin{array}{l}\text { Fluctuating cognition, delirium } \\
\text { episodes, and sleep disturbances }\end{array}$} & $\begin{array}{l}\text { When assessing cognition, simultaneously also assess for } \\
\text { fluctuations, ideally using a structured tool (e.g. Clinician } \\
\text { Assessment of Fluctuation scale or the Mayo Fluctuation } \\
\text { Composite Score) }\end{array}$ & $\begin{array}{l}\text { Develop a better understanding of the longitudinal } \\
\text { course of fluctuations in DLB }\end{array}$ \\
\hline & $\begin{array}{l}\text { Routinely assess patients with DLB for REM sleep } \\
\text { behaviour disorder and other sleep disturbances }\end{array}$ & $\begin{array}{l}\text { Assess the impact of REM sleep behaviour disorder, } \\
\text { insomnia, and daytime sleepiness (as well as their } \\
\text { treatments) on cognitive decline in cohorts of patients } \\
\text { with established DLB }\end{array}$ \\
\hline $\begin{array}{l}\text { Neuropathological co- and } \\
\text { multi-morbidity }\end{array}$ & $\begin{array}{l}\text { Establish clinical features of possible comorbid AD (using } \\
\text { cognitive testing, CSF, or neuroimaging) }\end{array}$ & $\begin{array}{l}\text { Larger clinico-pathological studies exploring the relative } \\
\text { influence of amyloid-beta, tau, alpha-synuclein, } \\
\text { cerebrovascular damage, TDP-43, and hippocampal } \\
\text { sclerosis on cognitive decline and the general clinical } \\
\text { picture }\end{array}$ \\
\hline
\end{tabular}

DLB, dementia with Lewy bodies; AD, Alzheimer's disease; MCI, mild cognitive impairment; MCI-LB, mild cognitive impairment with Lewy bodies; MoCA, Montreal Cognitive Assessment; REM, Rapid Eye Movement; CSF, cerebrospinal fluid.

vices, often below $5 \%$, with large geographical variations [2]. Compared to other forms of dementia, including Alzheimer's disease (AD), DLB is known to have a less favourable prognosis in a number of domains including an almost 2 years earlier mortality, higher rates of hospitalisation and institutionalization, more frequent episodes of delirium, lower quality of life, and higher caregiver burden and healthcare costs [3-10]. Less certainty exists in relation to cognitive decline in DLB despite a progressive cognitive impairment being a cardinal feature of all dementias. Although several current studies $[11,12]$ suggest an accelerated cognitive decline compared to $\mathrm{AD}$, the most recent meta-analysis found no difference between DLB and AD [13]. This review aims to outline challenges in predicting cognitive decline in DLB, to provide potential solutions for the practicing clinicians and to set future research directions (see Table 1 for an overview).

\section{Challenges due to a Delayed Diagnosis of Dementia with Lewy Bodies}

The prevalence of DLB amongst dementia subtypes diagnosed in memory services is about a quarter to onethird of what be expected from autopsy studies and DLB thereby seems substantially under-recognized [2]. A delay in DLB diagnosis is well-described in the literature: in the USA, more than 1 year was needed to establish the correct diagnosis of DLB for almost $50 \%$ of patients [14]. Similarly, in the UK, it took on average 1.2 years to arrive at a diagnosis of DLB from the initial appointment and more imaging and clinical assessments were needed than for patients with non-DLB diagnoses [15]. The impact of this delay in diagnosis on predicting cognitive decline is not clear. This, however, leads to the absence of a consistent point from which deterioration could be measured. Patients with DLB and AD are in most studies diagnosed 
with similar Mini-Mental State Examination scores (MMSE) [16], whereby scores in DLB patients are often slightly higher than in AD cohorts. A meta-analysis of survival data showed that differences in survival time were not explained by MMSE score at the time of diagnosis [8]. However, a study which measured survival from fixed MMSE score points of 20 and 17 showed that DLB had a shorter survival than $\mathrm{AD}$ when following up from each of these score points [17]. This could possibly indicate that at a higher MMSE score, the neurodegenerative process could already be further advanced in DLB. The variable ways in which DLB can present poses a challenge for clinical services. In a recent study of 251 patients diagnosed with DLB in a UK mental health and dementia care service, the most common early complaints were memory loss, but also hallucinations and low mood [18].

Early correct diagnosis of DLB remains an important challenge and an important step forward is the recent definition of research criteria for mild cognitive impairment (MCI) in DLB (MCI-LB) [19]. As in other already established diagnostic standards for MCI in neurodegenerative conditions, the triad of a subjective cognitive concern, an objective impairment in at least one cognitive domain, and largely preserved independent functioning needs to be met [20]. The cognitive impairment can be in any domain, but in the context of DLB, it is more likely to be associated with visuospatial, attentional, or executive deficits. For a diagnosis of MCI-LB, the authors propose that additional core features of DLB (fluctuating cognition, recurrent visual hallucinations, REM sleep behaviour disorder (RBD), at least one Parkinsonian motor sign) and/or proposed biomarkers (reduced dopamine transporter uptake in basal ganglia demonstrated by SPECT or PET, polysomnographic confirmation of REM sleep without atonia, and reduced meta-iodobenzylguanidine uptake on myocardial scintigraphy) need to be present [19]. Depending on the number of symptoms and biomarkers elicited, the research criteria support the diagnosis of either "probable" MCI-LB (at least 2 core features or one core feature and at least one biomarker present) or "possible" MCI-LB (only one core feature or biomarker present).

Another important concept is "mild behavioural impairment," which was developed mirroring MCI to detect behavioural changes occurring in later life, which do not meet the criteria for a major psychiatric disorder or dementia [21]. Neuropsychiatric symptoms, even if mild and occurring in the absence of an obvious cognitive impairment, have been shown to be associated with an increased dementia risk $[22,23]$. Although not formally op-

Cognitive Decline in DLB erationalized, a psychiatric-onset DLB has been proposed [19], whereby more severe new-onset psychiatric presentations, as late-onset major depressive disorder and lateonset psychosis should raise the suspicion of underlying Lewy body pathology. In these presentations, cognitive testing and evaluation of the patient's performance are challenging, both due to overlapping psychiatric symptoms and the propensity of patients with DLB to fluctuate in presentation. It has been shown that careful observation of the phenomenology (DLB presenting with more visual hallucinations and less paranoia than very-late-onset schizophrenia-like psychosis), and the neuropsychological profile (DLB presenting with prominent visuospatial deficits) can aid differential diagnosis between neurodegenerative and functional psychosis [24]. A higher frequency of hypersensitivity to any psychotropic medication and autonomic failure (ventilatory response to hypercapnia) can further predict DLB in those with lateonset depression [25]. In clinical reality, the use of biomarkerssuggested as usefulin MCI-LB, mightsupplement, or replace, these complex observations, but their clinical and economic value will need to be demonstrated [19, 26].

Overall, the variation of the time point and severity at which DLB is diagnosed makes it difficult to establish a clear baseline from which further decline can be monitored. The recent establishment of research criteria for MCI-LB and the increasing availability of biomarkers are important steps to facilitate earlier diagnosis and to improve monitoring of cognition. In cohorts which have been identified as at risk prior to receiving the diagnosis of dementia, there might be less heterogeneity between patients when the diagnosis is established. This should make it easier to synchronize cognitive trajectories and allow more coherent prediction of progression of cognitive decline [27].

\section{Challenges with Structured Cognitive Tests Used to Diagnose Dementia with Lewy Bodies and to Measure Change Over Time}

In contrast to $\mathrm{AD}$, which is primarily characterised by impaired memory and language, there is a higher occurrence of difficulties in attentional, executive, and visuoperceptual domains in DLB [28]. As DLB and dementia in Parkinson's disease (PDD) have an overlapping cognitive profile, recommendations regarding screening for PDD are likely to be useful for DLB. The Movement Disorder Society review committee recently endorsed 
[29] the Montreal Cognitive Assessment (MoCA) [30], Mattis Dementia Rating Scale Second Edition (DRS-2) [31], and the PD-Cognitive Rating Scale (PD-CRS) [32] for cognitive screening in Parkinson's disease. Not recommended were the scales most frequently used in clinical dementia services, the Mini-Mental State Examination (MMSE) [16] and the Adenbrooks's Cognitive Examination (ACE-R/ACE-III) [33, 34]. The MMSE is considered unsuitable as it primarily tests cortical aspects of cognition, as memory and language, which are frequently preserved in PDD or DLB (also subsumed as Lewy body dementias; LBD), with insufficient testing of visuospatial and executive function [29]. The ACE-R/ ACE-III [33] has good psychometric properties and assesses visuospatial function to a larger degree but has incomplete coverage of executive function, limited to only fluency tasks [29]. In contrast to the Mattis Dementia Rating Scale (DRS-2) and the MMSE, the MoCA has been shown to predict progression from MCI to PDD [35] as well as sensitivity to change over time in Parkinson's disease without dementia [36]. In the latter longitudinal study of 102 patients with PD, lower MoCA scores, postural instability and gait disturbance, and depressive symptoms at baseline were associated with a higher risk of cognitive decline [36]. However, little is known how structured tests can evaluate cognitive decline in those with Lewy body disease who have already reached the dementia stage. The rate of cognitive decline in LBD has been assessed in a number of longitudinal studies, largely using the MMSE, and the latest meta-analysis found similar decline in LBD and $\mathrm{AD}$ [13]. It has been speculated that this lack of difference might be grounded in the MMSE being not sensitive enough in registering cognitive deficits specific to LBD [37]. Differences in the rate of change between MMSE and MoCA were evaluated over 1 year in fourteen patients with DLB: no significant difference between the decline on MMSE (0.98-point decline) and the MoCA (1.04-point decline) was detected, with a trend of MoCA being more sensitive in identifying cognitive decline in patients with a milder cognitive impairment [37]. This underlines that larger follow-up studies regularly applying MoCA over several years are needed to elucidate its usefulness for cognitive prognostication in DLB.

Visuospatial functioning has been identified as potential predictor of faster cognitive and functional decline in DLB $[38,39]$. However, a more recent study of 67 patients with DLB followed for up to 4 years [40] found no significant association between low visuospatial scores at baseline and faster cognitive decline (measured by
MMSE) or progression of dementia severity. The same study assessed cognitive decline on a number of domainspecific tests in patients with DLB comparatively to 119 patients with $\mathrm{AD}$ [40]. A difference in the rate of cognitive decline between DLB and AD was only detected in the Trail Making Test A (TMT-A), which assesses visual scanning, psychomotor speed, and attention by asking the participant to draw a line to connect consecutive numbers from 1 to 25 [41]. Older studies also identified that patients with DLB declined slower in recognition memory and recall, but more rapidly in verbal fluency than those with AD [42-44].

Overall, assessment of cognition in DLB should not rely on tests predominantly assessing language and memory, and the MoCA appears to be a useful tool to detect cognitive difficulties and progression to dementia. Larger scale evaluations are required in patients who have already been diagnosed with DLB, both to determine MoCA's (or similar tests') performance and domain-specific decline.

\section{Challenges due to Fluctuating Cognition, Delirium Episodes, and Sleep Disorders}

Fluctuations are one of the core features of DLB and present in the majority of patients [45]. The term is used to describe spontaneous variations of cognitive abilities, alertness, or arousal [28]. Importantly those periods of impaired cognition occur on a spectrum between very marked changes (often described as delirium-like) to mild episodes of reduced responsiveness and alternate with close-to-normal cognitive performance [46]. Periods of apparent lucidity may be triggered by a novel environment or formal assessment, for example, in an outpatient clinic, and this could lead to improved performance in cognitive testing. The duration and pattern of fluctuations can be highly variable, from very short (lasting minutes to hours) to longer episodes (lasting days). Hence, these are unlikely to be noted by the clinician during a single clinical encounter but could potentially lead to differing outcomes, and possibly improvements, in consecutive assessments. Fluctuations do not tend to follow a diurnal rhythm and several forms of fluctuations (both in terms of duration and severity) may occur in the same patient [46]. This is also reflected in the longitudinal assessment of cognition in patients with DLB over time. Patients with Lewy body pathology have been described to have a greater variation across annual mean cognitive decline [47], and in the largest clinical study assessing
Tsamakis/Mueller 
cognitive decline in DLB, recruiting more than 800 patients, $18 \%$ of patients had an improved MMSE score 2 years after baseline [12].

Delirium (or acute confusional state) has been described as an early feature of DLB, and delirium-onset DLB has been proposed in the research criteria for prodromal DLB $[19,48]$. The authors suggest suspecting prodromal DLB when no adequate trigger for the delirium episode is found, when the delirium is recurrent or prolonged, and/or when the delirium leads to progressive cognitive decline [19]. While the higher occurrence of delirium in the early/prodromal/pre-diagnosis stage is welldescribed, recent research has also shown that patients with DLB remain at an increased risk of delirium compared to those with $\mathrm{AD}$ after a diagnosis of dementia is established [5]. This could reflect a misinterpretation of marked fluctuations (with clouding of consciousness and confusion) as delirium, DLB patients' increased vulnerability for developing delirium episodes, or a combination of both factors [19].

In addition to potentially affecting the outcome of cognitive testing, delirium episodes occurring in those with established dementia are known to accelerate cognitive decline. Cognitive decline triggered by delirium has been shown to be more rapid than can be explained by the neurodegenerative disease or the processes driving the delirium alone [49]. However, patients with Lewy body pathology form a minority in studies examining the interaction between delirium and neurodegeneration, and their trajectory following delirium episodes remains unclear. It is important to recognise that a delirium episode might be in the context of (potentially undiagnosed) DLB, to apply caution when considering treatment with antipsychotic medications, which are associated with severe adverse outcomes in DLB $[4,19]$.

While disturbed sleep is an established risk factor for cognitive decline and development of dementia [50], and there appears to be a particularly increased risk for those with RBD to develop an alpha-synucleinopathy as DLB [51], less is known about how sleep disturbances affect prognosis in those with an established diagnosis of DLB [52]. In all-cause dementia, sleep disturbances are associated with a poorer prognosis, including a higher frequency of neuropsychiatric symptoms and worse quality of life, as well as more severe cognitive decline [52]. The association between dementia and sleep disturbances is considered bidirectional, whereby the brain pathology can lead to disturbed sleep, and the sleep disturbance to accelerated cognitive decline [52]. Considering the strong link between RBD and DLB [53], it is likely that these re- lationships with adverse outcomes are also relevant for DLB and proactive identification of difficulties sleeping is important in clinical practice [54]. However, studies explicitly assessing the effect of sleep disturbances in patients with established DLB are lacking. In addition to $\mathrm{RBD}$, there would be value in evaluating the impact of insomnia and excessive daytime sleepiness. All 3 are common in alpha-synucleinopathies [55] but require differing treatments and might thereby lead to variations in cognitive trajectories [52].

Overall, delirium episodes, whether recognised or unrecognised, as well as potentially overlapping cognitive fluctuations, might contribute to the nonlinear, difficultto-predict course of cognitive decline in DLB. Concurrently assessing cognition and fluctuations using a semiquantitative scale (e.g., the Clinician Assessment of Fluctuation scale [56] or the Mayo Fluctuation Composite Score [57]) could make it easier to contextualize the cognitive scores and improve prediction of cognitive decline in patients with DLB. Sleep difficulties are likely to influence cognitive decline in DLB. It is important that those are recognised in routine practice and their impact on cognitive trajectories studied in cohorts of patients with established DLB.

\section{Challenges due to Neuropathological Co- and Multi-Morbidity}

Lewy body pathology is independently linked to cognitive decline $[47,58]$ and the distribution of Lewy bodies in different regions of the brain may influence their effect on cognition. Most relevant are probably limbic and neocortical Lewy bodies [47], but brain stem Lewy body pathology might also play a role [59]. It is now recognized that most patients with the clinical syndrome of dementia have mixed neuropathologies [60]. The impact of Lewy body pathology on cognitive loss varies at a person-specific level depending on additional brain pathologies present [58], whereby the most frequently occurring overlap with $\mathrm{AD}$ pathology (reported in at least twothirds of cases of DLB) has an additional effect leading to accelerated cognitive decline. While earlier studies detected the $\mathrm{AD}$ pathological substrate post-mortem [61, 62], more recent work used cerebrospinal fluid (CSF) analysis [63]. An "Alzheimer's" CSF pattern with higher total-tau and lower amyloid-beta- 42 has been linked to worse performance in MMSE subtests assessing memory and orientation in patients with DLB [64]. Further, abnormal CSF amyloid-beta- 42 has been shown to be more 
common in those with medial temporal lobe atrophy on MRI scans $[65,66]$.

However, in Boyle and colleagues' study [58] on mixed pathologies using the Religious Orders Study and the Memory and Aging Project, of 143 patients with cortical Lewy bodies, only 5 (4\%) had pure Lewy body pathology (i.e. without additional neuropathologies). Besides $\mathrm{AD}$, which was very common comorbidly with Lewy bodies (73\%), other pathologies also occurred frequently, and at a similar rate to other studies $[67,68]$. These included gross infarcts (34\%), microinfarcts (26\%), transactive response DNA-binding protein 43 (TDP-43, 41\%), and hippocampal sclerosis (12\%). These pathologies were often detected in combination and more than a third of the full cohort of more than 1,000 patients had 4 or more concomitant pathologies [58].

Overall, comorbid Alzheimer's pathology has consistently been implicated in a more rapid cognitive decline in patients with $\mathrm{DLB}$, and indicators of AD pathology are amnestic impairments in cognitive testing, an "Alzheimer's" CSF patterns and medial temporal lobe atrophy. However, the impact of other pathologies on cognitive decline in DLB, especially in the context of multiple pathologies, remains unclear and requires further exploration in larger clinico-pathological cohorts [69].

\section{Conclusion}

Dementia is a multifactorial condition with highly variable disease progression, and this is particularly relevant for DLB [27]. During the disease course of DLB numerous complex processes interact and cognitive decline is often determined by several neurodegenerative pathologies as well as comorbid physical and mental health conditions $[70,71]$.

Challenges in relation to cognitive prognostication in DLB highlighted in this review are: making a timely diagnosis and establishing a consistent baseline from which decline can be measured, using tests sufficiently assessing domains affected by DLB to monitor decline, as well as continued awareness of other factors that can affect cognitive performance and considering the interplay between differing brain pathologies. Further, for patients with Parkinson's spectrum disorders, as DLB, access to clinics for diagnosis and monitoring can be difficult due to motor or neuropsychiatric symptoms [72]. Hence, it has been highlighted that remotely collected data can reduce the need to commute for these patients while providing real-time insights into disease progression and treatment response [73]. These novel digital healthcare solutions could assist in addressing some of the challenges in relation to detecting DLB and monitoring cognitive decline $[73,74]$. Of particular interest are fluctuations, visual hallucinations, and autonomic instability. Remote monitoring of thermoregulation or cardiovascular parameters, as hypotension, could feed into assessments leading to an earlier diagnosis. Remote EEG [75] could, besides aiding detection of visual hallucinations, also measure fluctuations [73], one of the main challenges in predicting cognitive decline. Further research is needed to validate tools like the MoCA [30] in longitudinal studies, to determine the influence of delirium episodes on the disease course of DLB, and to develop a more fine-grained definition of clinico-pathological phenotypes potentially diagnosable through biomarkers.

\section{Conflict of Interest Statement}

The authors have no conflicts of interest to declare.

\section{Funding Sources}

C.M. receives salary support from the National Institute for Health Research (NIHR) Biomedical Research Centre at South London and Maudsley N.H.S. Foundation Trust and King's College London. The views expressed are those of the author(s) and not necessarily those of the N.H.S., the NIHR, or the Department of Health and Social Care.

\section{Author Contributions}

K.T. and C.M. jointly prepared and reviewed the manuscript and approved the version submitted to the journal.

\section{References}

1 Aarsland D, Ballard C, McKeith I, Perry RH, Larsen JP. Comparison of extrapyramidal signs in dementia with Lewy bodies and Parkinson's disease. J Neuropsychiatry Clin Neurosci. 2001;13(3):374-9.

2 Kane JPM, Surendranathan A, Bentley A, Barker SAH, Taylor J-P, Thomas AJ, et al. Clinical prevalence of Lewy body dementia. Alz Res Ther. 2018 Feb 15;10(1):19.

3 Bjoerke-Bertheussen J, Ehrt U, Rongve A, Ballard C, Aarsland D. Neuropsychiatric symptoms in mild dementia with lewy bodies and Alzheimer's disease. Dement Geriatr Cogn Disord. 2012;34(1):1-6.

4 Mueller C, Ballard C, Corbett A, Aarsland D. The prognosis of dementia with Lewy bodies. Lancet Neurol. 2017 May;16(5):390-8.
Tsamakis/Mueller 
5 FitzGerald JM, Perera G, Chang-Tave A, Price A, Rajkumar AP, Bhattarai M, et al. The incidence of recorded delirium episodes before and after dementia diagnosis: differences between dementia with Lewy bodies and Alzheimer's disease. J Am Med Dir Assoc. 2018 Nov 15;20(5):604-609.

6 Mueller C, Perera G, Rajkumar A, Bhattarai M, Price A, O'Brien J, et al. Hospitalization in people with dementia with Lewy bodies: frequency, duration, and cost implications. Alzheimers Dement. 2018;10:143-52.

7 Chen Y, Wilson L, Kornak J, Dudley RA, Merrilees J, Bonasera SJ, et al. The costs of dementia subtypes to California Medicare fee-forservice, 2015. Alzheimers Dement. 2019 Jul; 15(7):899-906.

8 Mueller C, Soysal P, Rongve A, Isik AT, Thompson T, Maggi S, et al. Survival time and differences between dementia with Lewy bodies and Alzheimer's disease following diagnosis: a meta-analysis of longitudinal studies. Ageing Res Rev. 2019 Jan 6;50:72-80.

9 van de Beek M, van Steenoven I, Ramakers IHGB, Aalten P, Koek HL, Olde Rikkert MGM, et al. Trajectories and determinants of quality of life in dementia with Lewy bodies and Alzheimer's disease. J Alzheimers Dis. 2019;70(2):389-97.

10 Gkotsis G, Mueller C, Dobson RJB, Hubbard TJP, Dutta R. Mining social media data to study the consequences of dementia diagnosis on caregivers rnd Relatives. Dement Geriatr Cogn Disord. 2020;49(3):295-302.

11 Rongve A, Soennesyn H, Skogseth R, Oesterhus R, Hortobágyi T, Ballard C, et al. Cognitive decline in dementia with Lewy bodies: a 5 -year prospective cohort study. BMJ Open. 2016 Feb 29;6(2):e010357.

12 Kramberger MG, Auestad B, Garcia-Ptacek S, Abdelnour C, Olmo JG, Walker Z, et al. Longterm cognitive decline in dementia with Lewy bodies in a large multicenter, international cohort. J Alzheimers Dis. 2017;57(3):787-95.

13 Breitve MH, Chwiszczuk LJ, Hynninen MJ, Rongve A, Brønnick K, Janvin C, et al. A systematic review of cognitive decline in dementia with Lewy bodies versus Alzheimer's disease. Alzheimers Res Ther. 2014;6(5-8):53.

14 Galvin JE, Duda JE, Kaufer DI, Lippa CF, Taylor A, Zarit SH. Lewy body dementia: the caregiver experience of clinical care. Parkinsonism Relat Disord. 2010 Jul;16(6):388-92.

15 Surendranathan A, Kane JPM, Bentley A, Barker SAH, Taylor JP, Thomas AJ, et al. Clinical diagnosis of Lewy body dementia. BJPsych Open. 2020 Jun 16;6(4):e61.

16 Folstein MF, Folstein SE, McHugh PR. "Minimental state". A practical method for grading the cognitive state of patients for the clinician. J Psychiatr Res. 1975 Nov; 12(3):189-98.

17 Stubendorff K, Hansson O, Minthon L, Londos E. Differences in survival between patients with dementia with Lewy bodies and patients with Alzheimer's disease: measured from a fixed cognitive level. Dement Geriatr Cogn Disord. 2011;32(6):408-16.
18 Moylett S, Price A, Cardinal RN, Aarsland D, Mueller C, Stewart R, et al. Clinical presentation, diagnostic features, and mortality in dementia with Lewy bodies. J Alzheimers Dis. 2019;67(3):995-1005.

19 McKeith IG, Ferman TJ, Thomas AJ, Blanc F, Boeve BF, Fujishiro H, et al. Research criteria for the diagnosis of prodromal dementia with Lewy bodies. Neurology. 2020 Apr 28;94(17): $743-55$.

20 Albert MS, DeKosky ST, Dickson D, Dubois B, Feldman HH, Fox NC, et al. The diagnosis of mild cognitive impairment due to $\mathrm{Alz}$ heimer's disease: recommendations from the National Institute on Aging-Alzheimer's Association workgroups on diagnostic guidelines for Alzheimer's disease. Alzheimers Dement. 2011 May;7(3):270-9.

21 Ismail Z, Agüera-Ortiz L, Brodaty H, Cieslak A, Cummings J, Fischer CE, et al. The mild behavioral impairment checklist (MBI-C): a rating scale for neuropsychiatric symptoms in pre-dementia populations. J Alzheimers Dis. 2017;56(3):929-38.

22 Creese B, Brooker H, Ismail Z, Wesnes KA, Hampshire A, Khan Z, et al. Mild behavioral impairment as a marker of cognitive decline in cognitively normal older adults. Am J Geriatr Psychiatry. 2019 Aug;27(8):823-34.

23 Martin E, Velayudhan L. Neuropsychiatric symptoms in mild cognitive impairment: a literature review. Dement Geriatr Cogn Disord. 2020 Apr 14:1-13.

24 Van Assche L, Van Aubel E, Van de Ven L, Bouckaert F, Luyten P, Vandenbulcke M. The neuropsychological profile and phenomenology of late onset psychosis: a cross-sectional study on the differential diagnosis of verylate-onset schizophrenia-like psychosis, dementia with Lewy bodies and Alzheimer's type dementia with psychosis. Arch Clin Neuropsychol. 2019 Mar 1;34(2):183-99.

25 Takahashi S, Mizukami K, Arai T, Ogawa R, Kikuchi N, Hattori S, et al. Ventilatory response to hypercapnia predicts dementia with Lewy bodies in late-onset major depressive disorder. J Alzheimers Dis. 2016;50(3): 751-8.

26 Fujishiro H, Iseki E, Nakamura S, Kasanuki K, Chiba Y, Ota K, et al. Dementia with Lewy bodies: early diagnostic challenges. Psychogeriatrics. 2013 Jun;13(2):128-38.

27 Melis RJF, Haaksma ML, Muniz-Terrera G. Understanding and predicting the longitudinal course of dementia. Curr Opin Psychiatry. 2019 Mar;32(2):123-9.

28 McKeith IG, Boeve BF, Dickson DW, Halliday G, Taylor JP, Weintraub D, et al. Diagnosis and management of dementia with Lewy bodies: fourth consensus report of the DLB Consortium. Neurology. 2017 Jul 4;89(1):88100.

29 Skorvanek M, Goldman JG, Jahanshahi M, Marras C, Rektorova I, Schmand B, et al. Global scales for cognitive screening in Parkinson's disease: critique and recommendations. Mov Disord. 2017 Nov 23.
30 Nasreddine ZS, Phillips NA, Bédirian V, Charbonneau S, Whitehead V, Collin I, et al. The montreal cognitive assessment, MoCA: a brief screening tool for mild cognitive impairment. J Am Geriatr Soc. 2005 Apr;53(4):6959.

31 Jurica P, Leitten C, Mattis S. Psychological assessment resources, 2001. Dementia rating scale-2 (DRS-2). Arch Clin Neuropsy. 2004; 19:145-7.

32 Pagonabarraga J, Kulisevsky J, Llebaria G, García-Sánchez C, Pascual-Sedano B, Gironell A. Parkinson's disease-cognitive rating scale: a new cognitive scale specific for Parkinson's disease. Mov Disord. 2008 May 15; 23(7):998-1005.

33 Mioshi E, Dawson K, Mitchell J, Arnold R, Hodges JR. The Addenbrooke's cognitive examination revised (ACE-R): a brief cognitive test battery for dementia screening. Int $J$ Geriatr Psychiatry. 2006 Nov;21(11):1078-85.

34 Hsieh S, Schubert S, Hoon C, Mioshi E, Hodges JR. Validation of the Addenbrooke's cognitive examination III in frontotemporal dementia and Alzheimer's disease. Dement Geriatr Cogn Disord. 2013;36(3-4):242-50.

35 Kim HM, Nazor C, Zabetian CP, Quinn JF, Chung KA, Hiller AL, et al. Prediction of cognitive progression in Parkinson's disease using three cognitive screening measures. Clin Park Relat Dis. 2019;1:91-7.

36 Chen L, Yu C, Zhang N, Liu J, Liu W. Cognitive impairment in patients with Parkinson's disease: a 30-month follow-up study. Clin Neurol Neurosurg. 2016 Dec;151:65-9.

37 Biundo R, Weis L, Bostantjopoulou S, Stefanova E, Falup-Pecurariu C, Kramberger MG, et al. MMSE and MoCA in Parkinson's disease and dementia with Lewy bodies: a multicenter 1-year follow-up study. J Neural Transm (Vienna). 2016 Apr;123(4):431-8.

38 Hamilton JM, Salmon DP, Galasko D, Raman R, Emond J, Hansen LA, et al. Visuospatial deficits predict rate of cognitive decline in autopsy-verified dementia with Lewy bodies. Neuropsychology. 2008 Nov; 22(6):729-37.

39 Wood JS, Watson R, Firbank MJ, Mosimann UP, Barber R, Blamire AM, et al. Longitudinal testing of visual perception in dementia with Lewy bodies and Alzheimer's disease. Int J Geriatr Psychiatry. 2013 Jun;28(6): 567-72.

40 Breitve MH, Chwiszczuk LJ, Brønnick K, Hynninen MJ, Auestad BH, Aarsland D, et al. A longitudinal study of neurocognition in dementia with Lewy bodies compared to Alzheimer's disease. Front Neurol. 2018;9: 124.

41 Reitan RM. Validity of the trail making test as an indicator of organic brain damage. Percept Mot Skills. 1958;8(3):271-6.

42 Ballard C, Patel A, Oyebode F, Wilcock G. Cognitive decline in patients with Alzheimer's disease, vascular dementia and senile dementia of Lewy body type. Age Ageing. 1996 May;25(3):209-13. 
43 Heyman A, Fillenbaum GG, Gearing M, Mirra SS, Welsh-Bohmer KA, Peterson B, et al. Comparison of Lewy body variant of Alzheimer's disease with pure Alzheimer's disease: consortium to establish a registry for Alzheimer's disease, part XIX. Neurology. 1999 Jun 10;52(9):1839-44.

44 Stavitsky K, Brickman AM, Scarmeas N, Torgan RL, Tang MX, Albert M, et al. The progression of cognition, psychiatric symptoms, and functional abilities in dementia with Lewy bodies and Alzheimer disease. Arch Neurol. 2006 Oct;63(10):1450-6.

45 Walker MP, Ayre GA, Cummings JL, Wesnes K, McKeith IG, O'Brien JT, et al. Quantifying fluctuation in dementia with Lewy bodies, Alzheimer's disease, and vascular dementia. Neurology. 2000 Apr 25;54(8):1616-25.

46 Matar E, Shine JM, Halliday GM, Lewis SJG. Cognitive fluctuations in Lewy body dementia: towards a pathophysiological framework. Brain. 2020 Jan 1;143(1):31-46.

47 Schneider JA, Arvanitakis Z, Yu L, Boyle PA, Leurgans SE, Bennett DA. Cognitive impairment, decline and fluctuations in older community-dwelling subjects with Lewy bodies. Brain. 2012 Oct;135(Pt 10):3005-14.

48 Gore RL, Vardy ER, O'Brien JT. Delirium and dementia with Lewy bodies: distinct diagnoses or part of the same spectrum? J Neurol Neurosurg Psychiatry. 2015 Jan;86(1):50-9.

49 Davis DH, Muniz-Terrera G, Keage HA, Stephan BC, Fleming J, Ince PG, et al. Association of delirium with cognitive decline in late life: a neuropathologic study of 3 population-based cohort studies. JAMA Psychiatry. 2017 Mar 1;74(3):244-51.

$50 \mathrm{Xu}$ W, Tan C-C, Zou J-J, Cao X-P, Tan L. Sleep problems and risk of all-cause cognitive decline or dementia: an updated systematic review and meta-analysis. J Neurol Neurosurg Psychiatry. 2020 Mar;91(3):236-44.

51 Postuma RB, Iranzo A, Hu M, Högl B, Boeve $\mathrm{BF}$, Manni R, et al. Risk and predictors of dementia and parkinsonism in idiopathic REM sleep behaviour disorder: a multicentre study. Brain. 2019 Mar 1;142(3):744-59.

52 Wennberg AMV, Wu MN, Rosenberg PB, Spira AP. Sleep disturbance, cognitive decline, and dementia: a review. Semin Neurol. 2017 Aug;37(4):395-406.

53 Boeve BF. REM sleep behavior disorder: updated review of the core features, the REM sleep behavior disorder-neurodegenerative disease association, evolving concepts, controversies, and future directions. Ann N Y Acad Sci. 2010 Jan;1184:15-54.
54 Thomas AJ, Taylor JP, McKeith I, Bamford C, Burn D, Allan L, et al. Development of assessment toolkits for improving the diagnosis of the Lewy body dementias: feasibility study within the DIAMOND Lewy study. Int J Geriatr Psychiatry. 2017 Dec;32(12):1280-304.

55 Barone P, Antonini A, Colosimo C, Marconi $\mathrm{R}$, Morgante L, Avarello TP, et al. The PRIAMO study: a multicenter assessment of nonmotor symptoms and their impact on quality of life in Parkinson's disease. Mov Disord. 2009 Aug 15;24(11):1641-9.

56 Walker MP, Ayre GA, Cummings JL, Wesnes $\mathrm{K}, \mathrm{McKeith}$ IG, O'Brien JT, et al. The clinician assessment of fluctuation and the one day fluctuation assessment scale. Two methods to assess fluctuating confusion in dementia. Br J Psychiatry. 2000 Sep;177:252-6.

57 Ferman TJ, Smith GE, Boeve BF, Ivnik RJ, Petersen RC, Knopman D, et al. DLB fluctuations: specific features that reliably differentiate DLB from AD and normal aging. Neurology. 2004 Jan 27;62(2):181-7.

58 Boyle PA, Yu L, Wilson RS, Leurgans SE, Schneider JA, Bennett DA. Person-specific contribution of neuropathologies to cognitive loss in old age. Ann Neurol. 2018 Jan;83(1): 74-83.

59 Keage HA, Ince PG, Matthews FE, Wharton SB, McKeith IG, Brayne C, et al. Impact of less common and "disregarded" neurodegenerative pathologies on dementia burden in a population-based cohort. J Alzheimers Dis. 2012; 28(2):485-93.

60 Kapasi A, DeCarli C, Schneider JA. Impact of multiple pathologies on the threshold for clinically overt dementia. Acta Neuropathol. 2017 Aug; 134(2):171-86.

61 Olichney JM, Galasko D, Salmon DP, Hofstetter CR, Hansen LA, Katzman R, et al. Cognitive decline is faster in Lewy body variant than in Alzheimer's disease. Neurology. 1998 Aug;51(2):351-7.

62 Nelson PT, Kryscio RJ, Jicha GA, Abner EL, Schmitt FA, Xu LO, et al. Relative preservation of MMSE scores in autopsy-proven dementia with Lewy bodies. Neurology. 2009 Oct 06;73(14):1127-33.

63 Abdelnour C, van Steenoven I, Londos E, Blanc F, Auestad B, Kramberger MG, et al. Alzheimer's disease cerebrospinal fluid biomarkers predict cognitive decline in lewy body dementia. Mov Disord. 2016 Aug;31(8): 1203-8.

64 Andersson M, Zetterberg H, Minthon L, Blennow K, Londos $\mathrm{E}$. The cognitive profile and CSF biomarkers in dementia with Lewy bodies and Parkinson's disease dementia. Int J Geriatr Psychiatry. 2011 Jan;26(1):100-5.

65 van der Zande JJ, Steenwijk MD, Ten Kate M, Wattjes MP, Scheltens P, Lemstra AW. Gray matter atrophy in dementia with Lewy bodies with and without concomitant Alzheimer's disease pathology. Neurobiol Aging. 2018 Nov;71:171-8.

66 Abdelnour C, Ferreira D, Oppedal K, Cavallin $\mathrm{L}$, Bousiges $\mathrm{O}$, Wahlund LO, et al. The combined effect of amyloid- $\beta$ and tau biomarkers on brain atrophy in dementia with Lewy bodies. Neuroimage Clin. 2020;27:102333.

67 Dugger BN, Adler CH, Shill HA, Caviness J, Jacobson S, Driver-Dunckley E, et al. Concomitant pathologies among a spectrum of parkinsonian disorders. Parkinsonism Relat Disord. 2014 May;20(5):525-9.

68 McAleese KE, Walker L, Erskine D, Thomas AJ, McKeith IG, Attems J. TDP-43 pathology in Alzheimer's disease, dementia with Lewy bodies and ageing. Brain Pathol. 2017 Jul; 27(4):472-9.

69 Spires-Jones TL, Attems J, Thal DR. Interactions of pathological proteins in neurodegenerative diseases. Acta Neuropathol. 2017 Aug; 134(2):187-205.

70 Soysal P, Perera G, Isik AT, Onder G, Petrovic $\mathrm{M}$, Cherubini A, et al. The relationship between polypharmacy and trajectories of cognitive decline in people with dementia: a large representative cohort study. Exp Gerontol. 2019 Mar 1.

71 Perera G, Mueller C, Stewart R. Factors associated with slow progression of cognitive impairment following first dementia diagnosis. Int J Geriatr Psychiatry. 2020 Sep 3.

72 Mueller C, Rajkumar AP, Wan YM, Velayudhan L, Ffytche D, Chaudhuri KR, et al. Assessment and management of neuropsychiatric symptoms in Parkinson's disease. CNS Drugs. 2018 Jul;32(7):621-35.

73 Owens AP, Ballard C, Beigi M, Kalafatis C, Brooker $\mathrm{H}$, Lavelle $\mathrm{G}$, et al. Implementing remote memory clinics to enhance clinical care during and after COVID-19. Front Psychiatry. 2020;11:579934.

74 Tsamakis K, Dimitrakakis G, Stefanadi E, Tsiptsios D, IAD, A Dimitrakaki I, et al. [Comment] The challenges of planetary mental health in the COVID-19 era. Exp Ther Med. 2020 Sep;20(3):1843-4.

75 Nasseri M, Nurse E, Glasstetter M, Bottcher S, Gregg NM, Laks Nandakumar A, et al. Signal quality and patient experience with wearable devices for epilepsy management. Epilepsia. 2020 Jun 4;61:S25-35. 